OPEN ACCESS

Edited by:

Han-Cheng Dan,

Central South University, China

Reviewed by:

Jizhe Zhang,

Shandong University, China

Qiao Dong

Southeast University, China

${ }^{*}$ Correspondence:

Xiang Ma

max@nifu.edu.cn

Specialty section:

This article was submitted to

Structural Materials,

a section of the journal

Frontiers in Materials

Received: 24 December 2021

Accepted: 27 December 2021

Published: 08 February 2022

Citation:

Ma X, Wang J and Xu Y (2022) Investigation on the Effects of RAP

Proportions on the Pavement

Performance of Recycled

Asphalt Mixtures.

Front. Mater. 8:842809.

doi: 10.3389/fmats.2021.842809

\section{Investigation on the Effects of RAP Proportions on the Pavement Performance of Recycled Asphalt Mixtures}

\author{
Xiang Ma*, Jiaqing Wang and Yinyin Xu \\ College of Civil Engineering, Nanjing Forestry University, Nanjing, China
}

In-plant hot mix recycling technology has been widely used in maintenance and reconstruction due to its good recycling performance. However, the utilization rate of recycled asphalt pavement (RAP) is still only $10-25 \%$, resulting in excessive accumulation and landfilling of RAP materials, which fails to promote the sustainable value of RAP in recycling. Therefore, this paper comprehensively explores the pavement performance of AC-20 ordinary asphalt recycled mixture and AC-13 modified asphalt recycled mixture with different proportions of RAP. The pavement performance test includes the dynamic modulus, rutting, dynamic creep, semicircular bending, and freeze-thaw splitting tests. The results show that, with the increase of RAP content, the mechanical properties and high-temperature properties of the two types of recycled asphalt mixtures are improved, the low temperature properties and moisture susceptibility properties are enhanced first and then weakened, and the best performance is reached when RAP content is 20 and $40 \%$, respectively. According to the entire pavement performance test results, the influence of RAP content on AC-13 recycled modified asphalt mixtures is relatively smaller than that of AC-20 normal recycled asphalt mixtures. The addition of rejuvenator can improve the low-temperature performance and moisture susceptibility of recycled asphalt mixtures to a certain extent, especially for AC-20 ordinary recycled asphalt mixture. Consequently, it is suggested to use AC-13 recycled modified asphalt mixture in the upper layer of road; the RAP content can reach $20 \%$, and rejuvenator can be used to improve its moisture susceptibility and low-temperature performance. AC-20 ordinary recycled asphalt mixture can be used in the middle surface layer, and the RAP content can reach $40 \%$, or using AC-13 recycled modified asphalt mixture, the RAP content can reach $50 \%$.

Keywords: hot in-plant reclaimed, RAP proportions, pavement performance, high-temp stability, low-temp cracking resistance, moisture susceptibility performance

\section{INTRODUCTION}

In the United States in 1975, the recycling of asphalt pavement reached 50,000 tons; in 1978, it reached more than 5 million tons, and through the end of the 1980s, the use of recycled asphalt mixes in the United States occupied 50\% of the national production of asphalt mixes and furthered related research, such as the development of regenerative agents and the mechanism of asphalt aging. 
Although the requirements of the major U.S. states (Thakur, 2010) on the proportion of old material blending are different, the blending rate is roughly $10-50 \%$, and the survey found that most of the asphalt pavement maintained by plant mix hot regeneration technology has a better road performance to meet the requirements of use. In the United States, the plant mix hot regeneration maintenance and repair technology is mainly used in road and airport runway paving (Kandhal et al., 1995). Germany, Finland, and other European countries in the mid-1970s also began to carry out research and exploration of asphalt pavement regeneration technology; the first country to apply asphalt recycled mixture in pavement maintenance and repair was Germany, and the effect is remarkable. In 1978, the recycling rate of old pavement materials reached $100 \%$. In Finland, the government called on all towns to actively carry out the recycling of pavement waste materials, and now the application of recycled materials has gradually expanded from low-to high-grade highway pavement. The most representative is the research report of NCHRP (Kandhal and Foo, 1997) (NCHRP Report452), which suggests that RAP not only plays the role of "black stone," but also the old asphalt coating on the surface still plays the role of bonding. Gaitan et al. (2013) studied the use of RAP in cold and hot recycled asphalt mixtures and analyzed the asphalt mastic in cold and hot recycled asphalt mixes, and the test results showed that the old material cold recycled was more active than hot recycled, and the degree of integration of new and old asphalt in hot recycled asphalt mixes was only $50-70 \%$, whereas cold recycled material was $20 \%$ higher, so a more in-depth study on the degree of integration of new and old asphalt in hot recycling is needed. Navaro et al. (2012) conducted a stratified extraction of asphalt in recycled asphalt mixes and used a combination of ultraviolet and infrared spectroscopy to determine the proportion of old and new asphalt in the mix. Experimental studies showed that the test process, temperature, and mixing time were the main factors affecting the mass fraction of old and new asphalt. Shane (Gundla and Underwood, 2017) mixed new and old asphalt and new and old aggregates in different proportions, and Arshad (Hussain and Yanjun, 2013) extracted and recovered the old asphalt from the RAP material and mixed it with different proportions of old and new asphalt and evaluated its performance. Luis (Loria et al., 2011) conducted a study on the road performance of hot mix asphalt pavements with up to $50 \%$ RAP in a region of Canada, and the results showed that the water damage resistance and low temperature crack resistance of high-RAP recycled materials could meet the requirements.

Since 2000, the aging phenomenon of asphalt pavement binders has been studied in depth in China, and its regeneration mechanism has also been systematically investigated. Jin et al. (2001) studied the changes in the composition and properties of road asphalt by using the thin film thermal aging method, and the test results showed that the aromatic fraction and gum content of the mixture decreased after aging, whereas the asphaltene content increased, and also, this change was in accordance with the macroscopic kinetic law. Chen and Chen (2008) found that the reactive groups in the internal molecules of asphalt react with oxygen in the air to form polar molecules, and oxygen and sulfur atoms are mostly present in asphalt molecules as carbonyl groups, sulfoxide functional groups, thioethers, and thiols, which he considered as the main cause of asphalt aging. The chemical composition and physical properties of asphalt are analyzed from two perspectives; in the chemical composition of asphalt after aging, the gum content is decreasing, asphalt content is increasing, and the physical indicators of the asphalt softening point has increased. Viscosity is also becoming larger, and needle penetration and ductility have decreased to a certain extent. Most domestic regeneration methods are based on the addition of light oil regenerants, but this regeneration method generally suffers from a lack of aging resistance (Ding, 2013). Domestic microscopic studies on asphalt are still mainly focused on the analysis of asphalt functional group changes using infrared spectroscopy and other means, and the research on microscopic analysis using atomic force microscopy is still relatively limited. Yang et al. (2015) and others studied the effect of three factors on the microstructure of asphalt by AFM, namely, the type of asphalt, short-term aging, and cooling rate during sample preparation, and found that the bee-type structures of different asphalts were very different, the quantities were somewhat different, and the sensitivity to short-term aging was also different. Zhao (Fan, 2016) used carbonyl and sulfoxide coefficients as the microscopic evaluation index of asphalt aging, which correlated well with the macroscopic mechanical index and could reasonably explain and evaluate the difference in performance of asphalt before and after aging.

Yang and Ma (2011) studied the effective regeneration rate of aging asphalt hot regeneration through experiments and found that there is a close relationship between the regeneration rate and aging asphalt preheating temperature, regenerant diffusion ability, and regenerated asphalt mixture mixing and time. Chen Yunqing (Chen, 2015) found that the moisture content of RAP material increased after aging, whereas the asphalt content decreased and the gradation occurred significantly refined. Meanwhile, the abrasion value and angularity of coarse aggregates in RAP material decreased to some extent, and the decline of limestone was small compared with basalt, but its wear resistance was obviously inferior to basalt. Shen (Shen and Wang, 2015) concluded that the RAP fineness modulus is the main factor affecting the volume parameters of asphalt recycled mixes, and the larger the RAP fineness modulus, the worse the high-temperature stability of the recycled material, whereas the degree of aging of asphalt has a small effect on the volume parameters of recycled mixes, but the effect on the mechanical properties of recycled material is greater, and the higher the degree of aging of asphalt in RAP material can improve the hightemperature stability of recycled material. The high temperature stability of the recycled material can be improved with higher aging of RAP material, but it is not good for moisture susceptibility. Zhao (2014) used the rutting test and Hamburg rutting test to evaluate and analyze the high-temperature performance of the recycled asphalt mixture, and it was found that the greater the amount of old material blended, the better the high temperature stability of the asphalt mixture. The moisture 
TABLE 1 | Results of recovered AC-20 common asphalt mix components.

\begin{tabular}{|c|c|c|c|c|c|c|c|c|c|c|c|c|}
\hline \multirow[t]{2}{*}{ Grouping } & \multicolumn{11}{|c|}{ Passing percentage of each sieve size $(\mathrm{mm})(\%)$} & \multirow{2}{*}{$\begin{array}{c}\text { Asphalt } \\
\text { content } \\
(\%)\end{array}$} \\
\hline & 19.0 & 16.0 & 13.2 & 9.5 & 4.75 & 2.36 & 1.18 & 0.6 & 0.3 & 0.15 & 0.075 & \\
\hline RAP & 97.3 & 86.3 & 73.4 & 60.7 & 42.6 & 23.7 & 16.3 & 11.7 & 6.9 & 5.1 & 3.9 & 3.8 \\
\hline Coarse & 97.9 & 85.2 & 72.5 & 60.3 & 39.7 & 24.6 & 15.8 & 10.8 & 5.8 & 4.9 & 3.7 & 3.6 \\
\hline \multicolumn{13}{|l|}{ RAP } \\
\hline Fine RAP & 100 & 100 & 100 & 100 & 100 & 49.8 & 33.9 & 25.6 & 14.1 & 10.7 & 7.5 & 4.1 \\
\hline
\end{tabular}

susceptibility was evaluated by using the water immersion Marshall test and freeze-thaw splitting test, and when the old material admixture ratio was lower than 50, there was little difference in moisture susceptibility performance compared with that of the brand new asphalt mixture. Yan and Xiao (2016) found through their study that increasing the RAP admixture can improve the high-temperature stability and water damage resistance of recycled asphalt mixes but has a negative impact on its low-temperature performance. Therefore, whereas increasing the proportion of RAP ensures its road performance meets the actual use requirements, the appropriate amount of regenerant can be introduced to improve the recycled asphalt mixture. At this stage, for a large amount of RAP material, recycled asphalt concrete and the synergistic mechanism between the regenerant is still to be clarified and the combination of different RAP and regenerant on the comprehensive road performance of recycled asphalt mixture research to be carried out.

The effect of the variation of RAP content on the road performance of different types of recycled asphalt mixes is considered for two different types of recycled asphalt mixes with high RAP content. The mechanical properties, hightemperature properties, low-temperature crack resistance, and moisture susceptibility are comprehensively studied by the variation of RAP admixture. The effect of the introduction of the regenerant on the road performance at higher RAP content (40\%) was also considered. The results show that the RAP content ratio can be appropriately increased in AC-13 modified recycled asphalt mix and AC-20 normal recycled asphalt mix to meet the requirements of the road, and the targeted addition of recyclers further improves its low-temperature performance and moisture susceptibility properties. The research results can provide an effective scientific basis and theoretical foundation for the efficient resource utilization of RAP admixture in practical projects.

\section{RAP COMPONENT ANALYSIS AND MIX RATIO DESIGN}

\subsection{RAP Component Analysis}

In this test, a milling speed of $15 \mathrm{~m} / \mathrm{min}$ was used to recycle the used materials. The old materials recovered in this study were AC20 common asphalt mixture and AC-13 modified asphalt mixture, and the extraction test was carried out using a fully automatic asphalt extraction instrument. At the same time, considering the large variability of the gradation of the old material, the uniformity of the mix design could not be guaranteed, so the old material was also divided into two grades: coarse and fine. First, the coarse and fine aggregates in the old material were separated as much as possible by heating, and then the separated old material was sieved into two components: coarse material (greater than $4.75 \mathrm{~mm}$ ) and fine material (less than $4.75 \mathrm{~mm}$ ). The sieving results of two kinds of asphalt mixes and the asphalt content of the mixes are shown in Tables 1, 2.

It can be seen that the asphalt content in the RAP materials both decreased to some extent (4.3 and 4.9\% for AC-20 and AC13 of the original pavement, respectively), indicating that the asphalt content continued to decrease during the aging process. Due to the adhesion property of the asphalt itself, it causes some of the fines to adhere to the surface of the coarse RAP material. Comparing the RAP test results with the coarse and fine RAP integration results, it can be found that the error between them is very small, indicating that the grade composition of the test and its asphalt content results are more reasonable.

\subsection{Recycled Asphalt Properties}

The 70\# common asphalt and SBS modified asphalt from the above recycled old material were used as the research objects. The mixture of extracted old asphalt and trichloroethylene was processed using a Swiss BuchiR-215V rotary evaporator, and the trichloroethylene in the mixture was removed by distillation and recycled. Then, the remaining pure asphalt was evaluated and analyzed, and the results were compared with the original values as shown in Tables 3, 4 .

From Tables 3, 4, in the recovery of two asphalt indicators it can be seen that needle penetration and ductility of the two old asphalts is significantly reduced and no longer meets the requirements of engineering technical indicators, whereas the softening point compared with the original indicators continues to increase. This is due to the asphalt in the aging process in the conversion between the components, the asphalt content is reduced, gum and asphaltene content increased, and asphalt molecular mass increased, making the recovered asphalt viscosity decreased, brittle, and hard.

\subsection{Optimal Asphalt Content}

The aggregate sieving tests for two types of recycled aggregates with different RAP admixtures were carried out based on the Aggregate Test Procedure for Highway Engineering (JTG E422005) with RAP admixtures of $20,30,40$, and $50 \%$, respectively.

At the same time, the Marshall mix design method was used to determine the $\mathrm{OAC}$, and the five asphalt contents used were 4.0, 
TABLE 2 | Results of recovered AC-13 modified asphalt mix components.

\begin{tabular}{|c|c|c|c|c|c|c|c|c|c|c|c|}
\hline \multirow[t]{2}{*}{ Grouping } & \multicolumn{10}{|c|}{ Passing percentage of each sieve size $(\mathrm{mm})(\%)$} & \multirow{2}{*}{$\begin{array}{c}\text { Asphalt } \\
\text { content } \\
(\%)\end{array}$} \\
\hline & 16.0 & 13.2 & 9.5 & 4.75 & 2.36 & 1.18 & 0.6 & 0.3 & 0.15 & 0.075 & \\
\hline RAP & 100 & 94.1 & 79.5 & 49.5 & 34.2 & 23.8 & 16.3 & 13.1 & 9.7 & 6.1 & 4.5 \\
\hline Coarse RAP & 100 & 94.8 & 79.0 & 45.8 & 32.1 & 22.5 & 15.2 & 12.0 & 8.6 & 4.5 & 4.2 \\
\hline Fine RAP & 100 & 100 & 100 & 100 & 76.1 & 51.9 & 34.1 & 24.8 & 16.9 & 10.3 & 4.8 \\
\hline
\end{tabular}

\begin{tabular}{|c|c|c|c|c|}
\hline Test index & $\begin{array}{l}\text { Test } \\
\text { results }\end{array}$ & $\begin{array}{l}\text { Original } \\
\text { value }\end{array}$ & $\begin{array}{l}\text { Technical } \\
\text { requirements }\end{array}$ & $\begin{array}{l}\text { Test method (Ministry of Transport of the People's Republic of } \\
\qquad \text { China, 2004) }\end{array}$ \\
\hline $\begin{array}{l}\text { Penetration }\left(25^{\circ} \mathrm{C} 100 \mathrm{~g} 5 \mathrm{~s}\right) \\
(0.1 \mathrm{~mm})\end{array}$ & 23.6 & 71.3 & $60-80$ & T0604-2000 \\
\hline Ductility ( $\left.15^{\circ} \mathrm{C} 5 \mathrm{~cm} / \mathrm{min}\right)(\mathrm{cm})$ & 55.4 & $>100$ & $\geq 100$ & T0605-1993 \\
\hline Softening point $\left({ }^{\circ} \mathrm{C}\right)$ & 62.5 & 46.5 & $\geq 46$ & T0606-2000 \\
\hline
\end{tabular}

TABLE 4 | Test index of recovered SBS modified asphalt.

\begin{tabular}{|c|c|c|c|c|}
\hline Test index & $\begin{array}{c}\text { Test } \\
\text { results }\end{array}$ & $\begin{array}{l}\text { Original } \\
\text { value }\end{array}$ & $\begin{array}{l}\text { Technical } \\
\text { requirements }\end{array}$ & $\begin{array}{l}\text { Test method (Ministry of Transport of the People's Republic of } \\
\qquad \text { China, 2004) }\end{array}$ \\
\hline $\begin{array}{l}\text { Penetration }\left(25^{\circ} \mathrm{C} 100 \mathrm{~g} 5 \mathrm{~s}\right) \\
(0.1 \mathrm{~mm})\end{array}$ & 30.8 & 66.2 & $50-80$ & T0604-2000 \\
\hline Ductility $\left(5^{\circ} \mathrm{C} 5 \mathrm{~cm} / \mathrm{min}\right)(\mathrm{cm})$ & 6.9 & 34.8 & $\geq 30$ & T0605-1993 \\
\hline Softening point $\left({ }^{\circ} \mathrm{C}\right)$ & 85.5 & 82.0 & $\geq 60$ & T0606-2000 \\
\hline
\end{tabular}

TABLE 5 | Summary results of the OAC for each asphalt recycled mixture.

\begin{tabular}{lcccc}
\hline Mixture type & \multicolumn{4}{c}{ Optimal asphalt content (\%) } \\
\cline { 2 - 5 } & 20\% RAP & 30\% RAP & 40\% RAP & 50\% RAP \\
\hline AC-20 & 4.2 & 4.2 & 4.3 & 4.2 \\
AC-13 & 4.8 & 4.9 & 4.9 & 4.8
\end{tabular}

4.5, 5.0, 5.5, and 6.0\%. Marshall specimens of $63.5 \mathrm{~mm}$ in height and $101.6 \mathrm{~mm}$ in diameter were formed. According to JTG F402004 (Ministry of Transport of the People's Republic of China, 2004), the OAC can be calculated based on the relationship between the asphalt content and the Marshall test indexes, including bulk density, air void, voids in the mineral aggregate (VMA), voids filled with asphalt (VFA), Marshall stability, and Marshall flow as shown in Table 5.

\section{TEST METHOD}

\subsection{Dynamic Modulus Test}

The test were conducted on the mechanical properties of AC-20 ordinary asphalt recycled mix and AC-13 modified asphalt recycled mix with different blending ratios $(0,20,40$, and $50 \%$, respectively) in which $5 \%$ of the same recycler is added to both recycled materials with $40 \%$ RAP blending for performance comparison. The heating temperature of RAP is $120^{\circ} \mathrm{C}$ for the best compaction characteristics of the mix (Ma et al., 2020), and the test at this temperature has a molding diameter of $150 \mathrm{~mm}$, height of $150 \mathrm{~mm}$ rotary compaction specimens and the number of compaction for 100 times, dynamic modulus test; the test process is shown in Figures 1A-C. Loading frequencies of 0.1, $0.5,1,5,10$, and $25 \mathrm{~Hz}$ were used for repeated loading tests under temperature conditions of $-10^{\circ} \mathrm{C}, 5^{\circ} \mathrm{C}, 20^{\circ} \mathrm{C}, 35^{\circ} \mathrm{C}$, and $50^{\circ} \mathrm{C}$, respectively, and the temperature was carried out from low to high temperatures, in turn, whereas the frequency was carried out from high to low frequency, in turn; the load and deformation curves of the last five waveforms were collected for the test, and the average of the three was taken for each specimen type as the final result. The average value of the three waveforms for each specimen type is taken as the final result. The test preparation and procedure are shown in Figure 1.

The dynamic modulus of the asphalt mixture at different temperatures can be established as a master curve with frequency at the same reference temperature, and the shift factor can be calculated from the corresponding model, of which the most commonly used is the WLF equation, as shown in Eq. 1.

$$
\log \alpha_{T}=\frac{C_{1}\left(T-T_{s}\right)}{C_{2}+T-T_{s}}
$$

where $\alpha_{T}$ is the shift factor at $T$ temperature conditions; $C_{1}, C_{2}$ are constants; $T_{S}$ is the reference temperature; and $T$ is the temperature of the individual test. 


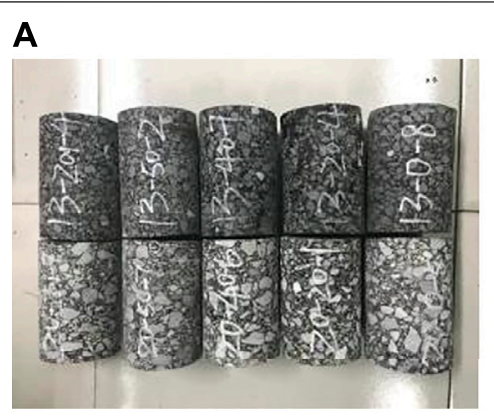

Core samples

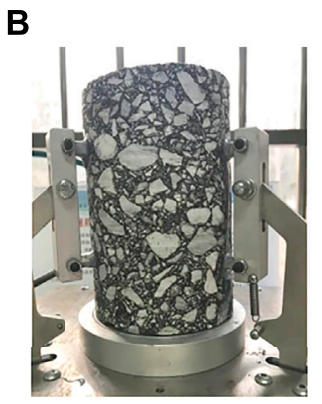

Sticky nails

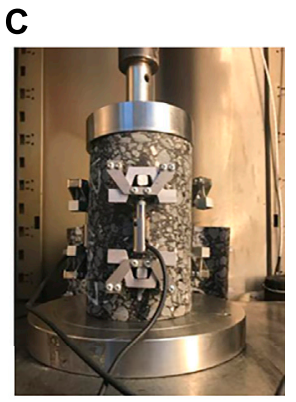

Applied load

FIGURE 1 | Dynamic modulus test procedure.

Pellinen (Pellinen et al., 2002) of the University of Maryland applied the least squares method to fit the sigmoidal equation and obtained the master curve by superposition of shift factors as in Eq. $\mathbf{2}$.

$$
\lg \left|E^{*}\right|=\delta+\frac{\alpha}{1+e^{\beta+\gamma * \lg (f r)}}
$$

where $\left|E^{*}\right|$ is the dynamic modulus value; $\delta$ is the minimum dynamic modulus value; $\alpha$ is the range of dynamic modulus values; $\beta, \gamma$ are the regression parameters; and $f r$ is scaling down the frequency, where the scaled-down frequency $f r$ and the frequency $f$ can be converted by the equation as in Eq. 3 .

$$
\lg (f r)=\lg (f)+\lg \left(a_{T}\right)
$$

where $\mathrm{f}$ is the test frequency and $a_{T}$ is the time-temperature conversion factor, representing the translation distance of the dynamic modulus curve at each temperature to the curve at the reference temperature.

\subsection{High-Temperature Stability Test}

The high-temperature rutting and dynamic creep tests were used to evaluate the high-temperature performance of asphalt recycled mixes with different RAP content ratios. The rutting specimens were prepared based on the density of Marshall specimens, and the heating temperature of RAP is $120^{\circ} \mathrm{C}$. The high-temperature rutting test is used to characterize the high-temperature performance of the mixture by dynamic stability, and the average value of three for each specimen type is taken as the final result.

The dynamic creep test uses 150-mm-diameter and 150-mmheight rotating compacted specimens (forming conditions, specimen type, and dynamic modulus test are the same); $60^{\circ} \mathrm{C}$ is the test temperature, axial pressure is set at $700 \mathrm{kPa}$, surrounding pressure is 0 , loading cycle is $1 \mathrm{~s}$ until the specimen is damaged or the test time reaches $3 \mathrm{~h}$, and each specimen type takes the average value of the three specimen types as the final result.

\subsection{Low-Temperature Crack Resistance Test}

A $-10^{\circ} \mathrm{C}$ semicircular splitting test was conducted by using a semicircular specimen of $150 \mathrm{~mm}$ in diameter and $50 \mathrm{~mm}$ in height at the test temperature of $-10^{\circ} \mathrm{C}$. For the SCB test, the distance $S$ between the two round rod pivot points was also $12 \mathrm{~cm}$ (0.8 times the semicircular specimen), and the loading rate was $50 \mathrm{~mm} / \mathrm{min}$. The semicircular specimen was continuously loaded until its destruction in the test, and the load and displacement were recorded. The test was carried out by a UTM-25 multifunctional testing machine, and the average value of three for each specimen type was taken as the final result.

The stress and modulus equations for semicircular specimens are used as shown in Eqs 4, 5 (Molnernaar et al., 2002).

$$
\begin{aligned}
\sigma_{t} & =\frac{4.8 F}{B D} \\
M_{r} & =\frac{1.84 F}{B V}
\end{aligned}
$$

where $\sigma t$ is the bottom tensile stress ( $\mathrm{MPa}), F$ is the vertical direction load $(\mathrm{N}), D$ is the diameter of the specimen $(\mathrm{mm}), \mathrm{B}$ is the thickness of the specimen $(\mathrm{mm}), V$ is the vertical displacement at the bottom of the specimen (mm), and $M_{r}$ is the modulus ( $\mathrm{MPa}$ ).

\subsection{Moisture Susceptibility (Freeze-Thaw Splitting Test)}

The freeze-thaw splitting test was carried out with $150 \mathrm{~mm}$ diameter, $50 \mathrm{~mm}$ height, and 20 and $40 \%$ RAP content of recycled mixture semicircular specimens. The air void of the asphalt mixture is related to the compaction times and heating temperatures of RAP and influences the moisture susceptibility, so compaction times and heating temperature were considered during the test. The specimens were divided into two groups, one of which was first treated with freeze-thaw cycles and then put into a constant temperature water bath at $25^{\circ} \mathrm{C}$ for $2 \mathrm{~h}$, together with the other group of specimens for splitting test with a loading rate of $5 \mathrm{~mm} / \mathrm{min}$. The average value of the three tests was taken as the final result for each specimen type.

\section{ANALYSIS OF TEST RESULTS}

\subsection{Dynamic Modulus}

In this test, the test temperature of $20^{\circ} \mathrm{C}$ was used as the reference temperature, and $a_{T}$ was taken as 0 . The dynamic modulus values 
TABLE 6 | Master curve fitting equations for different asphalt recycled mixes at $20^{\circ} \mathrm{C}$.

\begin{tabular}{|c|c|c|c|}
\hline Recycled material type & RAP ratio (\%) & $\begin{array}{c}\text { Master } \\
\text { curve fitting equation }\end{array}$ & $R^{2}$ \\
\hline \multirow[t]{3}{*}{ AC-20 General } & 0 & $\lg |y|=-0.5327+\frac{5.1838}{1+e^{-1.7923-0.2127^{*} \lg x}}$ & $R^{2}=0.9993$ \\
\hline & 20 & $\lg |y|=1.6286+\frac{3.0361}{1+e^{-1.0695-0.2293^{*} \lg x}}$ & $R^{2}=0.9994$ \\
\hline & 50 & $\lg |y|=-0.7126+\frac{5.4748}{1+e^{-1.9831-0.1909^{*} \lg x}}$ & $R^{2}=0.9983$ \\
\hline \multirow[t]{4}{*}{ AC-13 modified } & 0 & $\lg |y|=2.1123+\frac{2.4605}{1+e^{-0.7344-0.2172^{*} \lg x}}$ & $R^{2}=0.9996$ \\
\hline & 20 & $\lg |y|=0.6008+\frac{3.9909}{1+e^{-1.4949-0.1952 * \lg x}}$ & $R^{2}=0.9991$ \\
\hline & 40 & $\lg |y|=-0.8353+\frac{5.4766}{1+e^{-1.8391-0.1869^{*} \lg x}}$ & $R^{2}=0.9978$ \\
\hline & 50 & $\lg |y|=1.0657+\frac{3.6196}{1+e^{-1.5355-0.2469 * \lg x}}$ & $R^{2}=0.9980$ \\
\hline
\end{tabular}

obtained for different loading frequencies at this temperature were first fitted to obtain the initial fitting equations. The initially obtained $\delta, \alpha, \beta$, and $\gamma$ were used as the initial values, fitted to determine the $a_{T}$ values corresponding to other test temperatures (Ma et al., 2008), and then the test values of frequency-dynamic modulus at different temperature conditions were leveled to finally obtain the master curve fitting equation at the reference temperature of $20^{\circ} \mathrm{C}$ as shown in Table 6 . The results of comparing the master curves of two types of asphalt recycled mixes under different RAP admixtures are shown in Figures 2, 3, respectively.

The dynamic modulus values of the two types of asphalt recycled mixes increased with the increase of loading frequency, but the degree of change was different for different RAP admixture mixes, indicating that the recycled material was sensitive to temperature changes. For the AC-20 common asphalt recycled mix, the temperature stability of the mix is as follows: $\mathrm{RAP} 0 \%<\mathrm{RAP} 20 \%<\mathrm{RAP} 50 \%<\mathrm{RAP} 40 \%$ + regenerator $<$ RAP40\%, which indicates that, compared with the new material, the recycled material has a better temperature stability after adding RAP material with the increase of RAP content showing a trend of increasing first and then decreasing in the content. The temperature stability of AC-13 modified asphalt recycled mix is as follows: $\mathrm{RAP} 40 \%+$ regenerator $<\mathrm{RAP} 50 \%<$ RAP $20 \%<$ RAP0\% $<$ RAP $40 \%$, in which the sensitivity of the mix to temperature after adding RAP material is not significantly different compared with the new material, but the temperature sensitivity of the recycled mixture was slightly better when the RAP content was $40 \%$, and the addition of the recycler was not conducive to the improvement of the temperature stability of the mixture. In addition, comparing the results of AC-13 and AC-20, it can be seen that the temperature sensitivity of AC-20 normal recycled asphalt mixture is influenced by the RAP content. The temperature sensitivity of AC-13 modified recycled asphalt mixture is weaker compared with AC-20 normal asphalt mixture. The results of dynamic modulus values of AC-20 ordinary asphalt recycled $\mathrm{mix}$ at high frequency (low temperature) with different RAP admixtures are: RAP0\% 


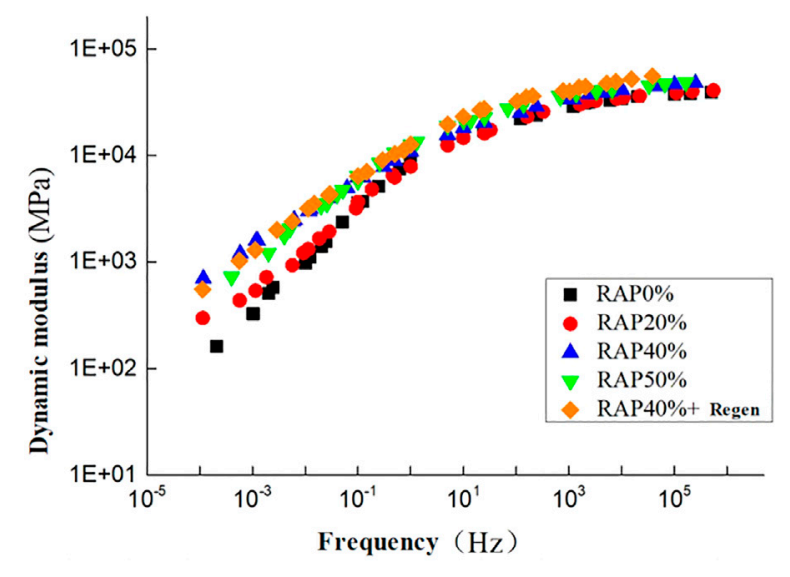

FIGURE 2 | Master curve of five different AC-20 normal asphalt recycled mixes.

$<$ RAP20\% < RAP40\% < RAP40\% + regenerator < RAP50\%, while the results of AC-13 modified asphalt recycled mix are: RAP $0 \%<$ RAP $20 \%<$ RAP $40 \%<$ RAP $50 \%<$ RAP40\% + regenerant. For the two different types of asphalt recycled mixes, the addition of the old material and the regenerant improved the mechanical strength of the mixes to some extent under high-frequency (low-temperature) conditions, and the higher the RAP content, the higher the strength, but considering the reduced flexibility of the recycled material, its anticracking performance at low temperature still needs further study. In addition, the RAP doping under low-frequency (hightemperature) conditions had a significant effect on the hightemperature stability of the AC-20 common asphalt recycled mix and had less effect on the AC-13 modified asphalt recycled mix. Meanwhile, the dynamic modulus values of AC-13 modified asphalt recycled mix with the same RAP content are basically higher than those of AC-20 ordinary asphalt recycled mix, indicating that the mechanical strength of AC-13 modified asphalt recycled mix is higher than that of AC-20 ordinary asphalt recycled mix.

\subsection{High-Temperature Stability \\ 4.1.1 Dynamic Stability}

The dynamic stability test results are shown in Figure 4. The dynamic stability of the recycled asphalt mixes with different RAP content met the technical requirements $(\geq 1,000$ times $/ \mathrm{min})$. With the increase of RAP, the dynamic stability of the two types of recycled asphalt gradually increased, and when the RAP mixture increased from 40 to $50 \%$, the growth rate became significantly larger, indicating that its high-temperature rutting resistance significantly improved. The softening point and viscosity of the recycled asphalt increase, thus showing increasing hightemperature performance. Comparing the two types of recycled material, it can be seen that the high-temperature stability of the AC-13 modified asphalt recycled mix is better than that of the AC-20 normal asphalt recycled mix as a whole.

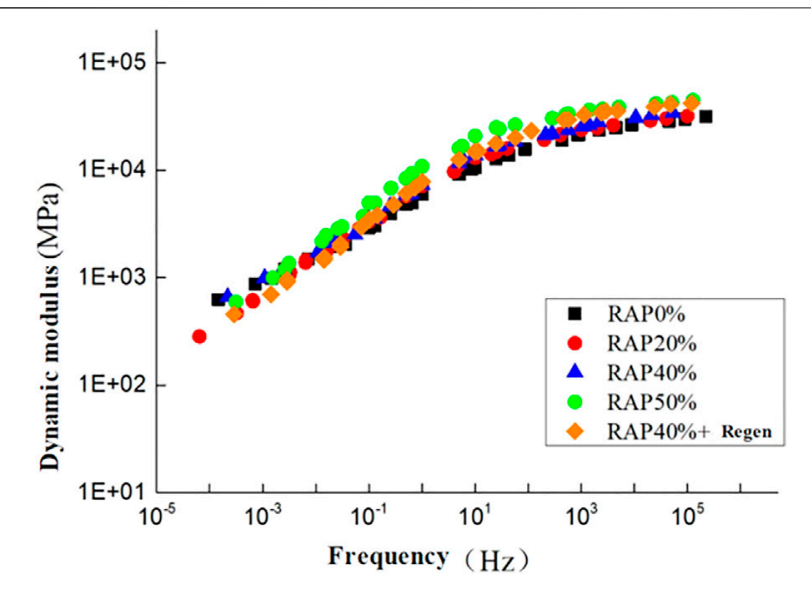

FIGURE 3 | Master curve of five different AC-13 modified asphalt recycled mixes.

\subsubsection{Dynamic Creep Cumulative Strain}

The dynamic creep cumulative strain curves of AC-20 normal asphalt recycled mix and AC-13 modified asphalt recycled mix with different RAP content are shown in Figures 5, 6. For the AC20 common asphalt recycled mix, the new material is the earliest to be damaged, the slope of the second stage is the largest, and the number of rheology is the smallest, only about 1,000 times. In addition, it can also be seen that the slope and strain of the second stage of the recycled material with $50 \%$ RAP is slightly greater than that of the recycled material with the addition of the recycler, and the performance of the two is similar, whereas both are significantly greater than the slope and strain of the recycled material with $40 \%$ RAP. For AC-13 modified asphalt recycled mixes, the third stage did not appear in any of the five different mixes, and the high-temperature rutting resistance of AC-13 modified asphalt recycled mixes with the same RAP content was better than that of AC-20 normal asphalt recycled mixes. Compared with the new material, the high-temperature rutting resistance of both types of recycled mixes with RAP was significantly improved, and the best high-temperature performance was achieved at $40 \%$ of RAP, and the hightemperature performance of AC-20 normal asphalt recycled mixes with this amount was close to that of AC-13 modified asphalt recycled mixes. In addition, the high-temperature rutting test and dynamic creep results are different, indicating that, for the high RAP mixture, it is not suitable to use a single index of dynamic stability and evaluate its high-temperature performance. It should be integrated with the dynamic creep test comprehensive evaluation.

\subsection{Low-Temperature Crack Resistance}

The critical value of bending strain energy density (Shan et al., 2019) was used as the main evaluation index of low-temperature performance. The semicircular splitting test indexes of 10 different asphalt recycled mixes at $-10^{\circ} \mathrm{C}$ low temperature are shown in Table 7. Under the same RAP content conditions, the 


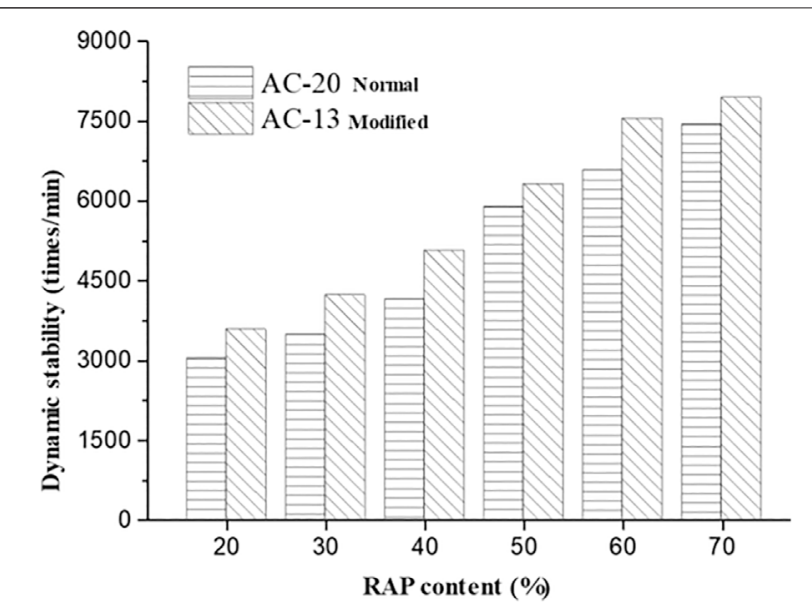

FIGURE 4 | Dynamic stability of asphalt recycled material with different RAP content.

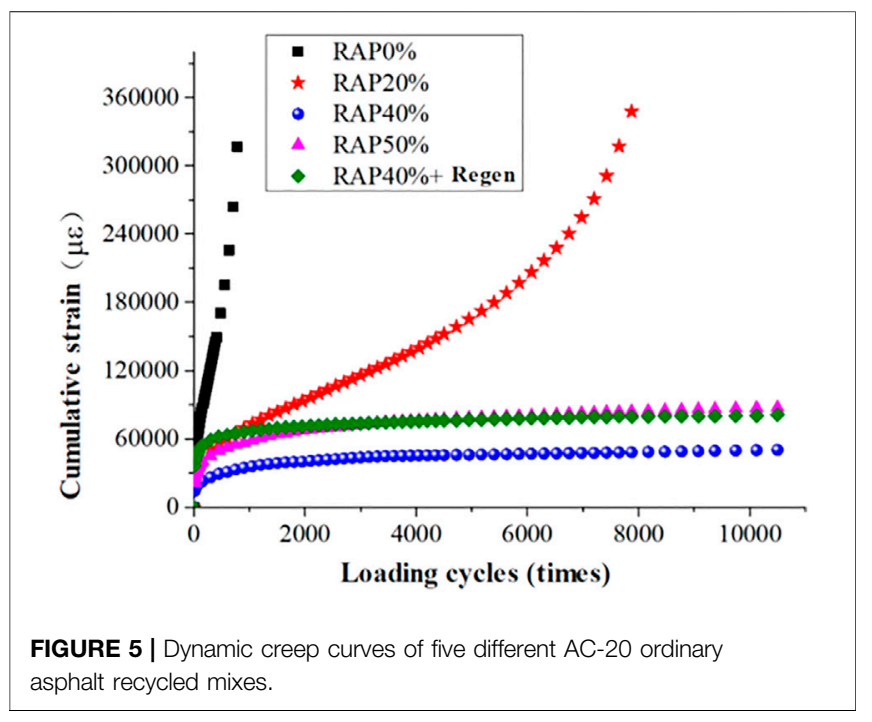

four indexes of the AC- 13 modified asphalt recycled mix are greater than the performance indexes of the AC-20 common asphalt recycled mix, which proves that the low-temperature performance of AC-13 modified asphalt recycled mix is more superior. The trend of bending and tensile strength and modulus of stiffness of both types of recycled mixes is the same: RAP0\% $<\mathrm{RAP} 20 \%<\mathrm{RAP} 40 \%<\mathrm{RAP} 40 \%$ + regenerator $<\mathrm{RAP} 50 \%$, whereas the trend of bending and tensile strain value is the opposite: RAP0\%>RAP20\% > RAP40\% + regenerator > RAP40\% > RAP50\%, which finally leads to the trend of strain energy density change: RAP20\% > RAP0\%>RAP $40 \%+$ regenerator > RAP $40 \%>$ RAP $50 \%$. Compared with the new material, only the low-temperature performance of the mixture with $20 \%$ RAP doping is improved, whereas continuing to increase the RAP doping will instead make its anticracking performance worse, and the higher the RAP doping, the worse the anticracking performance. In addition, the proportion of RAP

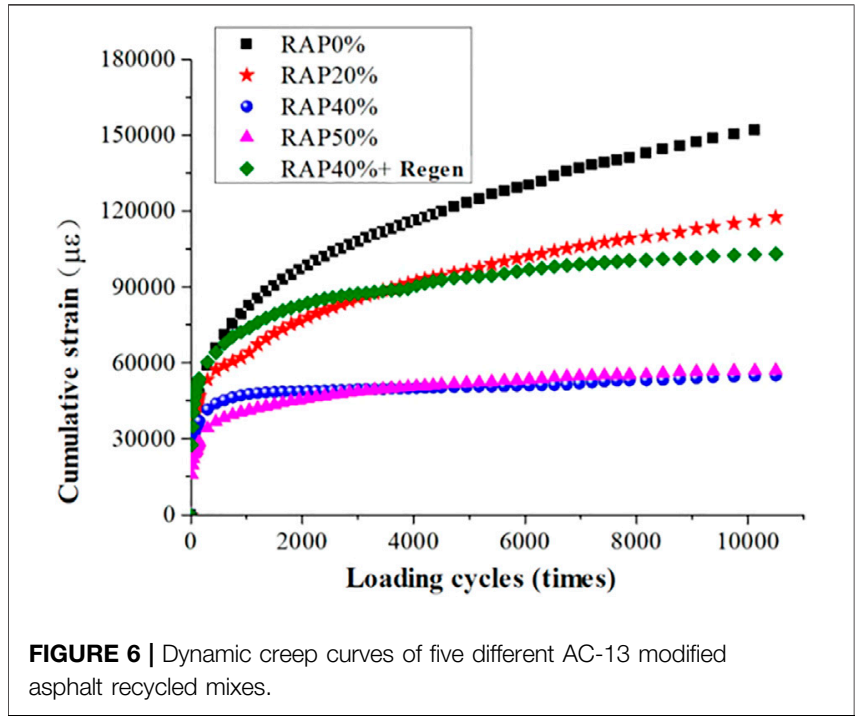

at $40 \%$ of the recycled mix after adding the regenerant four indicators have different degrees of increase, the regenerant in a certain degree makes the old and new asphalt mix combined more fully, and makes the brittle asphalt softened to a certain extent so as to enhance the toughness of the recycled mix and low-temperature cracking resistance.

\subsection{Moisture Susceptibility Performance}

The experimental results after freeze-thaw splitting tests with different RAP admixtures under different compaction times and heating temperatures are shown in Figure 7A-D. Considering the effect of heating temperature on the freeze-thaw splitting strength ratio TSR, it can be seen that, with the increase of heating temperature of the old material, the water damage resistance of the recycled asphalt mixture is significantly higher, and the difference between the performance of the mixture with the heating temperature of the old material above $120^{\circ} \mathrm{C}$ and that of the new material (RAP content is $0 \%$ ) is small, which indicates that increasing the heating temperature of the old material can effectively improve the moisture susceptibility of the mixture. Considering the effect of the RAP admixture on the moisture susceptibility performance of the recycled mix, it can be seen that, with the increase of the RAP admixture from 20 to $40 \%$, the freeze-thaw splitting tensile strength ratio of the mix increased slightly, and its water damage resistance increased slightly, but the enhancement effect on the moisture susceptibility performance was weak compared with the heating temperature. When considering the number of rotational compactions, the increase makes a small increase in the TSR value of the mix, which is due to the fact that the increase in the amount of compaction reduces the void ratio to a certain extent, improves the compactness of the mix, reduces the water infiltrated inside the mix during freeze-thaw, and shows better moisture susceptibility. Compared with the AC-20 ordinary asphalt recycled mix, the AC-13 modified asphalt recycled mix has higher splitting strength before and after freeze-thaw and has better resistance to water damage. 
TABLE 7 | Semicircular splitting test results of different asphalt recycled mixes $\left(-10^{\circ} \mathrm{C}\right)$.

\begin{tabular}{|c|c|c|c|c|c|}
\hline Mix type & $\begin{array}{l}\text { RAP content } \\
\text { (\%) }\end{array}$ & $\begin{array}{c}\text { Bending and } \\
\text { tensile strength } \\
\text { (MPa) }\end{array}$ & $\begin{array}{l}\text { Bending tensile } \\
\text { strain }(\mu \varepsilon)\end{array}$ & $\begin{array}{l}\text { Modulus of } \\
\text { rigidity (MPa) }\end{array}$ & $\begin{array}{c}\text { Strain energy } \\
\text { density }\left(\mathrm{KJ} / \mathrm{m}^{3}\right)\end{array}$ \\
\hline \multirow[t]{5}{*}{ AC-20 General } & $0 \%$ & 10.82 & 2,385 & 2,916 & 9.35 \\
\hline & $20 \%$ & 11.46 & 2,328 & 3,602 & 9.67 \\
\hline & $40 \%$ & 12.55 & 2,143 & 4,709 & 8.84 \\
\hline & $50 \%$ & 13.63 & 2000 & 5,244 & 8.65 \\
\hline & $40 \%+$ regenerant & 13.32 & 2,259 & 4,909 & 9.06 \\
\hline \multirow[t]{5}{*}{ AC-13 modified } & $0 \%$ & 12.17 & 2,853 & 3,647 & 13.35 \\
\hline & $20 \%$ & 12.95 & 2,822 & 3,964 & 13.60 \\
\hline & $40 \%$ & 13.39 & 2,768 & 4,985 & 13.16 \\
\hline & $50 \%$ & 13.98 & 2,683 & 5,610 & 12.92 \\
\hline & $40 \%+$ regenerant & 13.75 & 2,804 & 5,273 & 13.31 \\
\hline
\end{tabular}

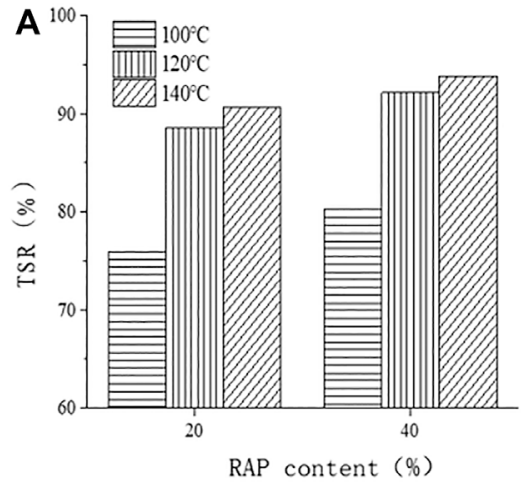

TSR of AC-20 ordinary asphalt recycled material compacted 100 times

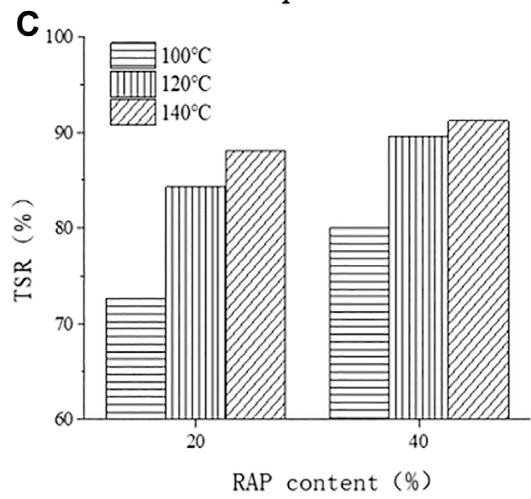

TSR of AC-13 ordinary asphalt recycled material compacted 100 times

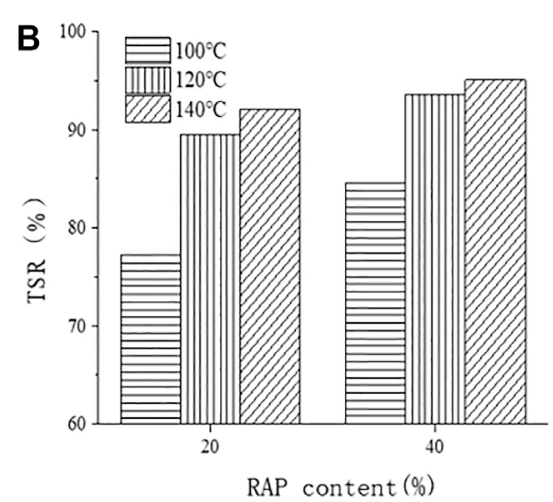

TSR of AC-20 ordinary asphalt recycled material compacted 160 times

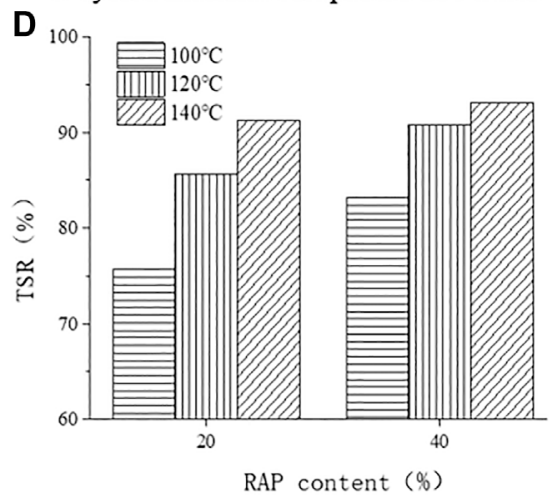

TSR of AC-13 ordinary asphalt recycled material compacted 160 times

\section{CONCLUSION}

The effects of RAP content $(0,20,40$, and $50 \%$ respectively) on the road performance of two different types of mixes, AC-20 normal asphalt recycled mix and AC-13 modified asphalt recycled mix, based on dynamic modulus, high- and low- temperature performance, and moisture susceptibility performance were investigated, and the main findings can be summarized as follows.

1 The addition of RAP and regenerant improved the dynamic modulus and mechanical strength of the recycled mixture, and 
the higher the RAP content, the higher the strength. Under low-frequency (high-temperature) conditions, the RAP content had a greater effect on the mechanical properties of AC-20 ordinary asphalt recycled mixes, but the mechanical properties of AC-13 modified asphalt recycled mixture has less effect.

2 Compared with the virgin asphalt mixture, the hightemperature rutting resistance of both types of recycled mixes with RAP were significantly improved, and the introduction of regenerant did not significantly improve the high-temperature rutting resistance. Compared with AC-20 ordinary asphalt recycled mix, the high-temperature rutting resistance of AC-13 modified asphalt recycled mix was better at the same RAP content level.

3 The low-temperature cracking resistance of the two different types of asphalt recycled mixes tended to increase with the increase of RAP content (from 0 to $50 \%$ ) and then weakened, and the best low-temperature performance was achieved when the RAP content was $20 \%$.

4 The moisture susceptibility of the two types of recycled mixtures showed a trend of increasing and then decreasing with the increase of RAP and reached the best state when the RAP was $40 \%$.

5 Under the high RAP content condition, the regenerant for road performance needs to be systematically analyzed according to the specific situation, and a single regenerant has a negative impact on the mechanical properties and hightemperature performance of the recycled mixture. Systematic analysis is needed to determine the appropriate RAP content

\section{REFERENCES}

Chen, H. X., and Chen, S. F. (2008). Aging Behavior and Aging Mechanism of Substrate Asphalt. J. Shandong Univ. Eng. Edition 38, 13-19. doi:10.3969/j.issn. 1671-5381.2009.01.004

Chen, Y. Q. (2015). Influence of Different Layers of Old Material Characteristics on the Road Performance of Hot Recycled Asphalt Mixtures. Master dissertation. Nanjing: Southeast University.

Ding, Z. (2013). Development and Application Research of Asphalt Mixture Regenerant for Waste Rubber Reuse. Master dissertation. Xi'an: Chang'an University.

Fan, Z. F. (2016). Microscale Study on the Evaluation of Asphalt Aging Performance. Master dissertation. Changsha: South China University of Technology.

Gaitan, L., Mehta, Y., Nolan, A., Dubois, E., Coffey, S., McCarthy, L., et al. (2013). Evaluation of the Degree of Blending and Polymer Degradation of Reclaimed Asphalt Pavement (RAP) for Warm Mix Asphalt. J. Solid Waste Technol. Mngmnt 39, 101-113. doi:10.5276/jswtm.2013.101

Gundla, A., and Underwood, S. (2017). Evaluation of In Situ RAP Binder Interaction in Asphalt Mastics Using Micromechanical Models. Int. J. Pavement Eng. 18, 798-810. doi:10.1080/10298436.2015.1066003

Hussain, A., and Yanjun, Q. (2013). Effect of Reclaimed Asphalt Pavement on the Properties of Asphalt Binders. Proced. Eng. 54, 840-850. doi:10.1016/j.proeng. 2013.03.077

Jin, M. L., Yang, J. H., and Shi, M. R. (2001). Analysis of the Aging Mechanism of Road Asphalt. J. Shanghai Inst. Appl. Tech. (Natural Sci. Edition) 1, 14-17. doi:10.3969/j.issn.1671-7333.2001.01.003

Kandhal, P. S., and Foo, K. Y. (1997). Designing Recycled Hot Mix Asphalt Mixtures Using Superpave Technology. Alabama: National Center for Asphalt Technology, 1-18. and regenerant use according to the actual project characteristics.

It is noteworthy that the content of RAP influences the performance of the recycled asphalt mixture, mainly because of interaction between virgin and aged asphalt binder. So, for future research, the blending between the virgin and aged asphalt binder is required to shed more light on the reasons.

\section{DATA AVAILABILITY STATEMENT}

The original contributions presented in the study are included in the article/Supplementary Material, further inquiries can be directed to the corresponding author.

\section{AUTHOR CONTRIBUTIONS}

Conceptualization, XM and JW; methodology, XM and JW; validation, XM and JW; formal analysis, XM; investigation, JW and $\mathrm{YX}$; data curation, XM; writing-original draft preparation, YX; writing-review and editing, JW.

\section{FUNDING}

The research was funded by the Jiangsu Transportation Scientific Research Project, Grant number 2017-21.

Kandhal, P. S., Rao, S. S., Watson, D. E., and Young, B. (1995). Performance of Recycled Hot Mix Asphalt Mixtures in State of Georgia. Transportation Res. Rec. 1507, 67-77.

Loria, L., Hajj, E. Y., Sebaaly, P. E., Barton, M., Kass, S., and Liske, T. (2011). Performance Evaluation of Asphalt Mixtures with High Recycled Asphalt Pavement Content. Transportation Res. Rec. 2208, 72-81. doi:10.3141/2208-10

Ma, X., Leng, Z., Wang, L., and Zhou, P. (2020). Effect of Reclaimed Asphalt Pavement Heating Temperature on the Compactability of Recycled Hot Mix Asphalt. Materials 13 (16), 3621. doi:10.3390/ma13163621

Ma, X., Ni, F. J., and Chen, R. S. (2008). Dynamic Modulus Test of Asphalt Mixture and Prediction Model. China J. Highw. Transport 21, 35-39. doi:10.19721/j. cnki.1001-7372.2008.03.007

Ministry of Transport of the People's Republic of China (2004). Technical Specifications for Construction of Highway Asphalt Pavements: JTG F40-2004. Beijing, China: China Communications Press.

Molnernaar, A., Scarpas, A., Liu, X., and Erkens, S. (2002). Semi-circular Bending Test; Simple but Useful. Asphalt Paving Technol. Assoc. Asphalt Paving Technologists-Proceedings Tech. Sessions 71, 794-815.

Navaro, J., Bruneau, D., Drouadaine, I., Pouteau, B., Colin, J., and Dony, A. (2012). Analyzing the Influence of Manufacturing Conditions of Reclaimed Asphalt concrete on the Characteristics of the Asphalt Binder: Development of a Gradual Binder Extraction Method. Eur. Phys. J. Appl. Phys. 58, 1-14. doi:10.1051/epjap/2012110102

Pellinen, T. K., Witczak, M. W., Marasteanu, M., Chehab, G., and Dongré, R. (2002). Stress Dependent Master Curve Construction for Dynamic (Complex) Modulus. Asphalt Paving Technol. Assoc. Asphalt Paving TechnologistsProceedings Tech. Sessions 71, 281-309.

Shan, M., Wang, L., and Zhang, B. (2019). Low Temperature Properties of WarmMixed Crumb Rubber Asphalt Mixture under Salt and Freeze-Thaw Cycles. J. Building Mater. 22, 467-473. doi:10.3969/j.issn.1007-9629.2019.03.20 
Shen, J., and Wang, X. H. (2015). Research on the Influence of Old Material Characteristics on the Performance of Plant-Mixed Hot Recycled Mixes. Inner Mongolia Road and Transportation 4, 48-51. doi:10.3969/j.issn.1005-0574. 2015.04.016

Thakur, S. C. (2010). Laboratory Evaluation of Characteristics of Recycled Asphalt Pavement (RAP) in Kansas. Doctoral Dissertation. Lawrence: University of Kansas.

Yan, X. Y., and Xiao, L. J. (2016). Research on the Road Performance of High-Dose RAP Plant-Mixed Hot Recycled Asphalt Mixes. Road Eng. 6, 76-77.

Yang, J., Gong, M. H., and Troy, P. (2015). Atomic Force Microscopy-Based Microstructure Study of Bitumen. J. Pet. (Petroleum Plus) 4, 959-965. doi:10. 3969/j.issn.1001-8719.2015.04.018

Yang, Y. W., and Ma, T. (2011). Detection Method of Effective Regeneration Rate of Aged Asphalt Hot Regeneration[J]. J. Construction Mater. 14, 418-422. doi:10.3969/j.issn.1007-9629.2011.03.025

Zhao, B. (2014). Research on the Mechanism and Technical Performance of Hot Regeneration of Asphalt Mixture. Master dissertation. Xi'an: Chang'an University.
Conflict of Interest: The authors declare that the research was conducted in the absence of any commercial or financial relationships that could be construed as a potential conflict of interest.

Publisher's Note: All claims expressed in this article are solely those of the authors and do not necessarily represent those of their affiliated organizations, or those of the publisher, the editors and the reviewers. Any product that may be evaluated in this article, or claim that may be made by its manufacturer, is not guaranteed or endorsed by the publisher.

Copyright $\odot 2022 \mathrm{Ma}$, Wang and Xu. This is an open-access article distributed under the terms of the Creative Commons Attribution License (CC BY). The use, distribution or reproduction in other forums is permitted, provided the original author(s) and the copyright owner(s) are credited and that the original publication in this journal is cited, in accordance with accepted academic practice. No use, distribution or reproduction is permitted which does not comply with these terms. 